\title{
Case report: nosocomial fungemia caused by Candida diddensiae
}

\author{
Seong Eun Kim', Sook In Jung ${ }^{1 *} \mathbb{D}$, Kyung-Hwa Park', Yong Jun $\mathrm{Choi}^{2}$, Eun Jeong Won ${ }^{2}$ and Jong Hee Shin ${ }^{2}$
}

\begin{abstract}
Background: Candida diddensiae, a yeast found in olive oil, is considered non-pathogenic to humans. Here, we describe the first case of fungemia caused by $C$. diddensiae in a hospitalized patient with underlying diseases.

Case presentation: A 62-year-old woman was admitted because of multiple contusions due to repeated falls and generalized weakness. She presented with chronic leukopenia due to systemic lupus erythematosus, and multiple cranial nerve neuropathies due to a recurring chordoma. She was given a lipid emulsion containing total parenteral nutrition (TPN) starting on the day of admission. Broad-spectrum antibiotics had been administered during her last hospital stay and from day 8 of this hospitalization. However, no central venous catheter was used during this hospital stay. Blood cultures obtained on hospital days 17, 23, and 24 yielded the same yeast, which was identified as C. diddensiae via sequence analyses of the internal transcribed spacer region and D1/D2 regions of the 26S ribosomal DNA of the rRNA gene. In vitro susceptibility testing showed that the minimum inhibitory concentration of fluconazole for all isolates was $8 \mu \mathrm{g} / \mathrm{mL}$. On day 23, TPN was discontinued and fluconazole therapy was started. Blood cultures obtained on day 26 were negative. The fluconazole therapy was replaced with micafungin on day 26 and the patient exhibited improvements.
\end{abstract}

Conclusion: The use of lipid TPN may potentially contribute to the occurrence of nosocomial fungemia by $C$. diddensiae, an unusual Candida species.

Keywords: Candida diddensiae, Fungemia, Leukopenia, Malignancy, Total parenteral nutrition

\section{Background}

Due to an increasing number of patients with impaired immune function and developments in medical interventions, some Candida species previously considered to be food yeasts or harmless commensals are emerging as causes of invasive disease [1]. Candida diddensiae has been considered non-pathogenic to humans but is a component of the olive oil microbiota that affects the quality of the oil [2]. Although rare, this organism has been isolated from the human gut [3,4], and one clinical isolate of $C$. diddensiae is included in a recent national surveillance dataset of invasive candidiasis in China [5].

\footnotetext{
* Correspondence: sijung@chonnam.ac.kr

${ }^{1}$ Department of Infectious Diseases, Chonnam National University Medical School, 42, Jebong Ro, Donggu, Gwangju 61469, Republic of Korea Full list of author information is available at the end of the article
}

However, no detailed clinical data have been presented, thus the potential of this organism for human infection remains unclear. Here, we describe a case of $C$. diddensiae fungemia in a hospitalized patient with intractable cancer and chronic leukopenia. To our knowledge, this is the first reported case of $C$. diddensiae fungemia.

\section{Case presentation}

A 62-year-old woman was admitted to a community hospital in Jangheung, South Korea for multiple contusions due to repeated falls. After admission, she was treated with antibiotics, urinary catheterization, and a commercial lipid emulsion-containing total parenteral nutrition (TPN). C. diddensiae fungemia was diagnosed based on positive blood cultures drawn from peripheral veins on hospitalization days 17, 23, and 24 (Fig. 1).

(c) The Author(s). 2020 Open Access This article is licensed under a Creative Commons Attribution 4.0 International License, which permits use, sharing, adaptation, distribution and reproduction in any medium or format, as long as you give appropriate credit to the original author(s) and the source, provide a link to the Creative Commons licence, and indicate if changes were made. The images or other third party material in this article are included in the article's Creative Commons licence, unless indicated otherwise in a credit line to the material. If material is not included in the article's Creative Commons licence and your intended use is not permitted by statutory regulation or exceeds the permitted use, you will need to obtain permission directly from the copyright holder. To view a copy of this licence, visit http://creativecommons.org/licenses/by/4.0/. The Creative Commons Public Domain Dedication waiver (http://creativecommons.org/publicdomain/zero/1.0/) applies to the data made available in this article, unless otherwise stated in a credit line to the data. 


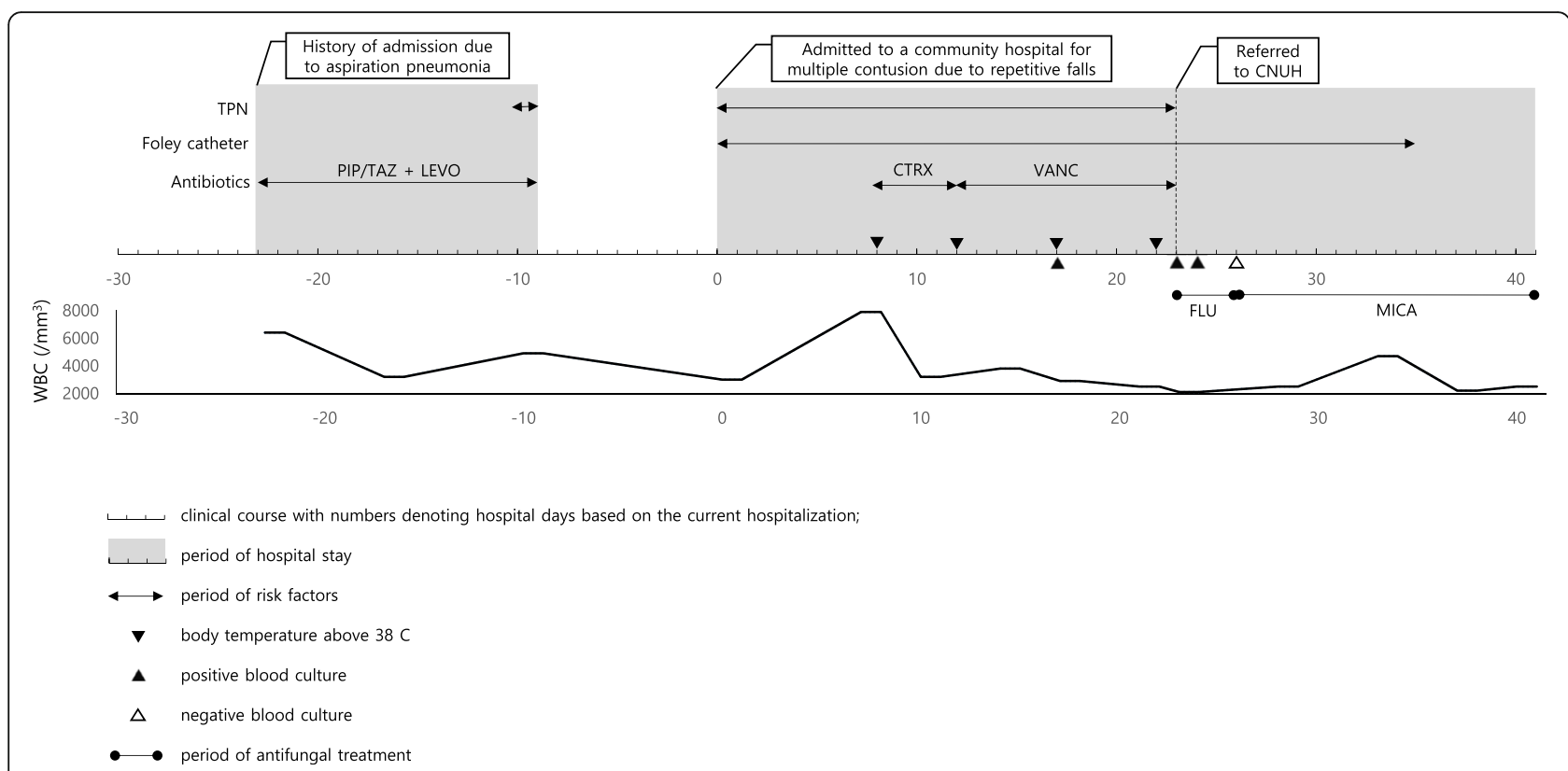

Fig. 1 Clinical course and treatment of the patient with C. diddensiae fungemia. TPN, total parenteral nutrition; PIP/TAZ, pipera cillin/tazobactam; LEVO, levofloxacin; CTRX, ceftriaxone; FLU, fluconazole; MICA, micafungin; WBC, white blood cell; CNUH, Chonnam National University Hospital

The patient had an 8-year history of systemic lupus erythematosus (SLE). From the time of SLE diagnosis, she had been taking methylprednisolone, azathioprine, and hydroxychloroquine sulfate and tapered them gradually. Her SLE has been well controlled without any medication for the past 2 years. Despite good control of SLE, chronic leukopenia of 2000 to $3000 / \mathrm{mm}^{3}$ (neutrophils 600 to $1500 / \mathrm{mm}^{3}$ ) persisted, and bone-marrow biopsy revealed hypocellularity of all cell lines without dyserythropoiesis or megakaryocytic atypia, which is typical of SLE. The patient had been diagnosed with a chordoma in the sphenoid sinus and clivus 5 years earlier. Despite repeated neurosurgery, the tumor progressed and resulted in multiple cranial nerve neuropathies. One month before hospitalization, the patient reported worsened difficulty in swallowing, and a physical examination revealed right vocal cord palsy and no right oropharyngeal lateral wall movement. Twenty-three days before this admission, she was admitted for aspiration pneumonia and given piperacillin/tazobactam and levofloxacin for 2 weeks. She has never received antifungal treatment.

A lipid emulsion containing TPN was started for nutrition support on day 1 of hospitalization and all infusions were completed within $24 \mathrm{~h}$ of initiating the fluid. On day 8 , the patient developed an intermittent fever (peak temperature $38.8^{\circ} \mathrm{C}$ ) that persisted for 14 days. Catheter-associated urinary tract infection was suspected and ceftriaxone was initiated after a urine culture was taken. The antibiotic was subsequently changed to vancomycin because the urine culture revealed the presence of ampicillin-resistant, vancomycin-susceptible
Enterococcus faecium. Chest and abdominal computed tomography did not reveal any focus of infection or perforation. Because blood cultures obtained on day 17 indicated the presence of a yeast, she was transferred to Chonnam National University Hospital (CNUH; Gwangju, South Korea) for the treatment of fungemia. Upon physical examination, there were no local inflammatory signs at the peripheral intravenous catheter sites, such as erythema, swelling or tenderness. On arrival at CNUH (on day 23), a follow-up blood culture was performed, and intravenous fluconazole was initiated empirically ( $800 \mathrm{mg}$ loading and then $400 \mathrm{mg} /$ day). The TPN was discontinued. An ophthalmological examination showed no evidence of endophthalmitis, and transthoracic echocardiography showed no evidence of endocarditis. On day 26 (4 days after $\mathrm{CNUH}$ admission), the fluconazole was replaced with micafungin $(100 \mathrm{mg} /$ day for 16 days) after 4 days of fluconazole treatment because of the high fluconazole minimum inhibitory concentration (MIC) in antifungal susceptibility tests. Follow-up blood cultures taken on day 26 were negative. The patient's condition improved and she was discharged on day 41 after supportive care and intravenous echinocandin treatment.

Six blood culture sets from peripheral blood obtained on days 17, 23, and 24 (two sets on each day) yielded the same yeast isolate. The isolate grew on sheep blood agar as non-hemolytic, white colonies after $48 \mathrm{~h}$ of incubation at $35^{\circ} \mathrm{C}$ in an aerobic environment, and yielded pink colonies on BBL CHROMagar Candida (BD Diagnostics, Franklin Lakes, NJ, USA). The isolates were analyzed by 
sequencing the internal transcribed spacer (ITS) and D1/D2 regions of the $26 \mathrm{~S}$ ribosomal DNA of their rRNA gene. The ITS region (including the 5.8S rRNA gene) and the D1/D2 domains of the 26S rRNA gene were amplified using the primer pairs pITS-F (5'-GTCGTA ACAAGGTTAACCTGCGG-3') and pITS-R (5'TCCTCCGCTTATTGATATGC-3') and NL1 (5'-GCATATCAATAAGCGGAGGAAAAG-3') and NL4 (5'GGTCCGTGTTTCAAGACGG-3') [6], respectively. The yeast was identified as $C$. diddensiae (GenBank accession no: KC253978 and MK394116.1) with 100\% homology using BLAST (www.ncbi.nlm.nih.gov/blast). The isolate was misidentified as Millerozyma farinosa (93\% probability) when the Vitek2 YST card (bioMérieux, Marcy l'Étoile, France) systems was used. Two commercial matrix-assisted laser desorption/ionizationtime of flight mass spectrometry (MALDI-TOF MS) systems, the VITEK MS (bioMérieux) with Knowledge Base ver. 3.0 and the MALDI-TOF Biotyper (Bruker Daltonics, Billerica, MA, USA) were not able to identify the yeast because $C$. diddensiae was not included in their databases. Antifungal susceptibility testing performed using the broth microdilution M27-A3 method of the Clinical and Laboratory Standards Institute (CLSI) produced following MICs: amphotericin B, $1 \mu \mathrm{g} / \mathrm{mL}$; fluconazole, $8 \mu \mathrm{g} / \mathrm{mL}$; voriconazole, $0.25 \mu \mathrm{g} / \mathrm{mL}$; caspofungin, $0.25 \mu \mathrm{g} / \mathrm{mL}$; and micafungin, $0.125 \mu \mathrm{g} / \mathrm{mL}$.

\section{Discussion and conclusion}

Candida species are a members of human mucosal and skin microbiotas, and most cases of fungemia involve endogenous flora [7]. However, C. diddensiae is not commonly found in healthy individuals. $C$. diddensiae was reported for the first time in extra virgin olive oil [2]. Recent research has demonstrated the presence of a rich microflora (mainly yeasts) in freshly produced olive oil [8]. In addition, $C$. diddensiae is a resident eukaryote in the infant gastrointestinal tract $[3,4,9]$. Our patient did not have a central venous catheter, so this foodassociated fungus most likely entered through the intestinal tract with the consumption of contaminated food. Although C. diddensiae colonization of the gastrointestinal tract before candidemia was not documented in this patient, broad-spectrum antibiotics might have affected the gut microbiota and the level of yeast colonization of the gastrointestinal tract $[10,11]$. The TPN infusion, broad-spectrum antibiotic use, and longterm neutropenia caused by SLE might have led to nosocomial fungemia by $C$. diddensiae in our patient with a recurring progressive chordoma.

Because the TPN infusate and peripheral catheters were not cultured, contamination of the TPN set or a peripheral catheter infection could not be excluded. However, the TPN sets were all changed within $24 \mathrm{~h}$ of initiating the fluid and the peripheral catheters were replaced within $96 \mathrm{~h}$ based on the guidelines for the prevention of intravascular catheter-related infection [12]. There were also no local signs of inflammation at the peripheral intravenous catheter sites, such as erythema, swelling, or tenderness. The TPN formula used for this patient contained a lipid emulsion. Although the role of lipid addition to TPN in fungal infections is not wellelucidated [13], recent research has shown that lipid emulsions induce Candida virulence determinants, such as germination and enhanced biofilm production, which may help to explain the increased risk of candidemia [14]. Our patient produced persistent positive blood cultures for $C$. diddensiae while she was receiving lipid TPN. Although the blood isolates had a relatively high fluconazole MIC $(8 \mu \mathrm{g} / \mathrm{mL})$, the candidemia cleared after 3 days of fluconazole and the discontinuation of TPN. Furthermore, the soybean oil of the lipid emulsion containing TPN and olive oil are composed of similar components $[15,16]$. These findings suggest that the lipid emulsion containing TPN might increase the risk of $C$. diddensiae fungemia by providing a favorable lipid-rich environment for $C$. diddensiae survival in the blood. Therefore, this case raises concerns about the potential contribution of lipid-emulsion-containing TPN use to the occurrence of $C$. diddensiae bloodstream infections.

The incidence of invasive fungal disease in patients with SLE is $0.6-3.2 \%[17,18]$. Invasive fungal disease is more likely to develop during the active stage of SLE. Although this patient was not at the active stage of SLE, long-lasting leukopenia caused by SLE induced bonemarrow failure and the resulting immune impairment might have contributed to the dissemination of candidemia [19-21]. Furthermore, leukopenia is a risk factor for candidemia caused by non-albicans Candida species compared with $C$. albicans $[22,23]$. These findings highlight the pathogenic potential of a relatively avirulent organism in the setting of immunosuppression.

Mycology laboratories are challenged by the identification and antifungal susceptibility testing of unusual, clinically significant yeasts. Our case shows that $C$. diddensiae cannot be correctly identified with commercial identification systems or two MALDI-TOF systems used in routine microbiology laboratories, because of the absence of this organism from their databases. Molecular methods were required for accurate identification.

The use of azole as a fungicide in agriculture and the persistence of fungicides in the environment promote the emergence and spread of azole-resistant fungi [24]. Several common Candida species that cause human disease, such as C. tropicalis, C. famata, C. guilliermondii, C. krusei, C. orthopsilosis, and C. parapsilosis, were detected on the surface of fruit purchased from supermarkets and $39 \%$ had a fluconazole MIC of $\geq 8 \mathrm{mg} / \mathrm{L}$ [25]. 
Although the CLSI has not established species-specific clinical breakpoints for $C$. diddensiae, the $C$. diddensiae isolated from the present case had a fluconazole MIC of $8 \mathrm{mg} / \mathrm{L}$, consistent with a previous report [5]. Therefore, uncommon Candida species isolated from blood samples should be identified and antifungal susceptibility testing performed to select the appropriate antifungal therapy.

This case suggests that $C$. diddensiae, which is considered non-pathogenic to humans and of industrial importance only, can be a pathogen and has the potential to cause bloodstream infection in immunocompromised patient. Unusual Candida species may vary greatly in their susceptibility to current antifungal agents, which can cause considerable issues in patient management [26].

\section{Abbreviations}

TPN: total parenteral nutrition; SLE: systemic lupus erythematosus; MALDITOF MS: matrix-assisted laser desorption/ionization-time of flight mass spectrometry; CLSI: Clinical and Laboratory Standards Institute;

MIC: minimum inhibitory concentration; CNUH: Chonnam National University Hospital

\section{Acknowledgements}

None.

\section{Authors' contributions}

SEK and SIJ participated in the clinical care of the patient on the ward. KHP, YJC, EJW, and JHS advised and supervised the laboratory testing, interpretation, and reporting. SIJ and JHS were responsible for the concept of, critical contributions to, and revision of this manuscript. SEK wrote the manuscript. All authors critically reviewed the manuscript for publication and read and approved the final version.

\section{Funding}

No funding was required for to write this case report.

\section{Availability of data and materials}

Not applicable (no datasets were generated or analyzed during this study).

\section{Ethics approval and consent to participate}

Not applicable.

\section{Consent for publication}

The patient provided written consent to publish this case report (Consent No. 2018-JN11).

\section{Competing interests}

The authors declare that they have no competing interests.

\section{Author details}

'Department of Infectious Diseases, Chonnam National University Medical School, 42, Jebong Ro, Donggu, Gwangju 61469, Republic of Korea. ${ }^{2}$ Department of Laboratory Medicine, Chonnam National University Medical School, Gwangju, Republic of Korea.

Received: 6 November 2019 Accepted: 15 May 2020

Published online: 27 May 2020

\section{References}

1. Johnson EM. Rare and emerging Candida species. Curr Fungal Infect R. 2009:3:152-9.

2. Zullo BA, Cioccia G, Ciafardini G. Distribution of dimorphic yeast species in commercial extra virgin olive oil. Food Microbiol. 2010;27:1035-42.

3. LaTuga MS, Ellis JC, Cotton CM, Goldberg RN, Wynn JL, Jackson RB, et al. Beyond bacteria: a study of the enteric microbial consortium in extremely low birth weight infants. PLoS One. 2011;6:e27858.
4. Hamad I, Raoult D, Bittar F. Repertory of eukaryotes (eukaryome) in the human gastrointestinal tract: taxonomy and detection methods. Parasite Immunol. 2016;38:12-36

5. Xiao M, Sun ZY, Kang M, Guo DW, Liao K, Chen SC, et al. Five-year National Surveillance of invasive candidiasis: species distribution and azole susceptibility from the China hospital invasive fungal surveillance net (CHIFNET) study. J Clin Microbiol. 2018;56:e00577-18.

6. Kim MN, Shin JH, Sung H, Lee K, Kim EC, Ryoo N, et al. Candida haemulonii and closely related species at 5 university hospitals in Korea: identification, antifungal susceptibility, and clinical features. Clin Infect Dis. 2009;48:e57-61.

7. Pfaller MA, Diekema DJ. Epidemiology of invasive candidiasis: a persistent public health problem. Clin Microbiol Rev. 2007;20:133-63.

8. Ciafardini G, Zullo BA. Microbiological activity in stored olive oil. Int J Food Microbiol. 2002; 75:111-8

9. Jones L, Kumar J, Mistry A, Sankar Chittoor Mana T, Perry G, Reddy VP, et al. The Transformative Possibilities of the Microbiota and Mycobiota for Health, Disease, Aging, and Technological Innovation. Biomedicines. 2019;7:E24.

10. Samonis G, Gikas A, Anaissie EJ, Vrenzos G, Maraki S, Tselentis Y, et al. Prospective evaluation of effects of broad-spectrum antibiotics on gastrointestinal yeast colonization of humans. Antimicrob Agents Chemother. 1993;37:51-3.

11. Samonis G, Anaissie EJ, Bodey GP. Effects of broad-spectrum antimicrobial agents on yeast colonization of the gastrointestinal tracts of mice. Antimicrob Agents Chemother. 1990;34:2420-2.

12. O'Grady NP, Alexander M, Burns LA, Dellinger EP, Garland J, Heard SO, et al. Guidelines for the prevention of intravascular catheter-related infections. Clin Infect Dis. 2011;52:e162-93.

13. Sriram K, Meguid MM. Addition of lipids to parenteral nutrition does not cause fungal infections. Nutrition. 2015;31:1443-6.

14. Swindell K, Lattif AA, Chandra J, Mukherjee PK, Ghannoum MA. Parenteral lipid emulsion induces germination of Candida albicans and increases biofilm formation on medical catheter surfaces. J Infect Dis. 2009;200:473-80.

15. Olive oil, salad or cooking, fat composition, 100 g. 2016. US National Nutrient Database Available: https://fdc.nal.usda.gov/fdc-app.html\#/?query= ndbNumber:4053.

16. Soybean oil, salad or cooking, fat composition, 100 g. 2016. US National Nutrient Database Available: https://fdc.nal.usda.gov/fdc-app.html\#/?query= ndbNumber:4044.

17. Wang LR, Barber $C E$, Johnson AS, Barnabe C. Invasive fungal disease in systemic lupus erythematosus: a systematic review of disease characteristics, risk factors, and prognosis. Semin Arthritis Rheum. 2014;44:325-30.

18. Lao M, Wang X, Ding M, Yang Z, Chen H, Liang L, et al. Invasive fungal disease in patients with systemic lupus erythematosus from southern China: a retrospective study. Lupus. 2019;28:77-85.

19. Koh AY, Kohler JR, Coggshall KT, Van Rooijen N, Pier GB. Mucosal damage and neutropenia are required for Candida albicans dissemination. PLoS Pathog. 2008:4:e35.

20. Wenzel RP. Nosocomial candidemia: risk factors and attributable mortality. Clin Infect Dis. 1995;20:1531-4.

21. Dewan E, Biswas D, Kakati B, Verma SK, Kotwal A, Oberoi A. Epidemiological and mycological characteristics of candidemia in patients with hematological malignancies attending a tertiary-care center in India. Hematol Oncol Stem Cell Ther. 2015;8:99-105.

22. Hachem R, Hanna H, Kontoyiannis D, Jiang Y, Raad I. The changing epidemiology of invasive candidiasis: Candida glabrata and Candida krusei as the leading causes of candidemia in hematologic malignancy. Cancer. 2008;112:2493-9.

23. Cheng MF, Yang YL, Yao TJ, Lin CY, Liu JS, Tang RB, et al. Risk factors for fatal candidemia caused by Candida albicans and non-albicans Candida species. BMC Infect Dis. 2005;5:22.

24. Chowdhary A, Kathuria S, Xu JP, Meis JF. Emergence of azole-resistant Aspergillus fumigatus strains due to agricultural azole use creates an increasing threat to human health. PLoS Pathog. 2013;9:e1003633.

25. Lo HJ, Tsai SH, Chu WL, Chen YZ, Zhou ZL, Chen HF, et al. Fruits as the vehicle of drug resistant pathogenic yeasts. J Inf Secur. 2017;75:254-62.

26. Arendrup MC, Patterson TF. Multidrug-Resistant Candida: Epidemiology, Molecular Mechanisms, and Treatment. J Infect Dis. 2017;216(suppl_3):S445-51.

\section{Publisher's Note}

Springer Nature remains neutral with regard to jurisdictional claims in published maps and institutional affiliations. 